Article

\title{
Creativity in Higher Education: A Qualitative Analysis of Experts' Views in Three Disciplines
}

\author{
Helen Georgiou ${ }^{1, *(\mathbb{D}}$, Annette Turney ${ }^{1}\left(\mathbb{D}\right.$, Erika Matruglio ${ }^{1}\left(\mathbb{D}\right.$, Pauline Jones $^{1}$, Paul Gardiner ${ }^{1}$ \\ and Christine Edwards-Groves ${ }^{2}$ D \\ 1 School of Education, University of Wollongong, Wollongong, NSW 2522, Australia; \\ aturney@uow.edu.au (A.T.); erikam@uow.edu.au (E.M.); paulinej@uow.edu.au (P.J.); paulg@uow.edu.au (P.G.) \\ 2 School of Education, Australian Catholic University, Fitzroy, VIC 3065, Australia; \\ christine.edwards-groves@acu.edu.au \\ * Correspondence: helengeo@uow.edu.au
}

Citation: Georgiou, H.; Turney, A.; Matruglio, E.; Jones, P.; Gardiner, P.; Edwards-Groves, C. Creativity in Higher Education: A Qualitative Analysis of Experts' Views in Three Disciplines. Educ. Sci. 2022, 12, 154 https://doi.org/10.3390/ educsci12030154

Academic Editor: Eleanor Dommett

Received: 21 January 2022

Accepted: 20 February 2022

Published: 23 February 2022

Publisher's Note: MDPI stays neutral with regard to jurisdictional claims in published maps and institutional affiliations.

Copyright: (C) 2022 by the authors. Licensee MDPI, Basel, Switzerland. This article is an open access article distributed under the terms and conditions of the Creative Commons Attribution (CC BY) license (https:// creativecommons.org/licenses/by/ $4.0 /)$.

\begin{abstract}
Creativity has been identified as an increasingly important graduate attribute for employment in the 21st century. As sites of significant development of disciplinary specialization, universities seem to be the natural place for creativity to be fostered. However, there remain contestations and ambiguities in the ways creativity is theorized, and this translates to difficulties in operationalization, particularly in the higher education context, which attracts significantly less research than the school setting. Here, we report on interviews with physicists, historians, and poets, as both educators and producers of knowledge that progresses their disciplines, to provide elaborations on the nature of creativity. We draw on sociological theory to elucidate the characteristics of creativity as expressed by experts in particular disciplinary fields. We find that whilst perceptions appear common across the disciplines, on further analysis, they tend instead to encapsulate discrete attributes. Further, there are some qualities of creativity that are uniquely emphasized by participants in specific disciplinary fields. We argue that theorizing both the discipline and the nature of creativity together is important in order to understand how creativity might more fruitfully be discussed and fostered in higher education.
\end{abstract}

Keywords: legitimation code theory; domain-specific creativity; curriculum; graduate attributes; qualitative analysis

\section{Introduction}

Creativity is recognized as playing an important role in personal well-being and in social and economic innovation and as such has prompted significant developments in education [1,2]. In Australia and beyond, creative and critical thinking skills have been embedded in school curricula, with efforts underway to design valid and reliable assessments of students' creativity [3,4]. Creativity is also identified by employers and universities as one of the attributes they desire to see in recent graduates [5,6]. Yet, while a considerable corpus of research into creativity in education exists, successfully fostering and assessing creativity in practice is notoriously difficult [7]. Further, the bulk of these assessment initiatives refer to school contexts; there is significantly less focus on creativity in higher education, where creative objectives in individual programs are often absent $[8,9]$.

In this paper, we analyse experts' views of creativity in their three respective disciplines (physics, history, and poetry). As producers of knowledge as well as teachers in the discipline, the experts' perspectives in this research offer an understanding of the scope and value of creativity. Drawing from theories in creativity and sociology, we relate disciplinary knowledge contexts to perceptions of creativity in an effort to better understand its nature and, in turn, how best to foster it. 


\section{Background}

Creativity has received considerable attention and is extensively characterized in the literature. Often defined as having a unique or novel idea that has value, e.g., [10], creativity is described as part of a system [11] or with reference to models outlining its different "types" [12] and "facets" [13]. Though some elements of creativity are almost universally acknowledged, it remains inconsistently defined, with its definition often described as being "contentious" [14]. The issue of ambiguity is discussed in the literature, in particular, the imprecision relating to what is meant by creativity in educational contexts [15-18]. Bleakley [18], for instance, explains that "the term is often employed uncritically, in the singular, and is reified" (p. 463).

Whilst creativity, when considered in its entirety, constitutes a range of different elements and dimensions, in the context of education, creativity is often conceptualized in terms of a set of creative attributes, habits, or thinking skills, e.g., [3,8,19-21]. For instance, in Australia, the national curriculum for schools identifies four main skill areas: inquiring, generating ideas, reflection, and analysis and synthesis [3]. Henriksen [19] similarly identifies the transdisciplinary skills of: observing, patterning, abstracting, embodied thinking, modelling, play, and synthesizing. In the higher education context, Jackson and Shaw [8] identify: being imaginative, being original, exploring, processing, analysing and synthesising data and ideas, and communicating, as skills that academics view as important. Again, in higher education, Jahnke et al. [20] identify the "facets" of self-reflective learning, independent learning, curiosity and motivation, producing something, showing multiple perspectives, and reaching for original, entirely new ideas.

There are slightly different variations on these descriptions across the literature, and it is also recognized that different disciplinary contexts influence the presence, significance, and meaning of such descriptions. Jahnke et al. [20], for instance, assert that disciplinary background is essential for understanding creativity in higher education. In their research surveying academics on their views on creativity, they found that social science-aligned academics tend to emphasize creativity as manifest when students are involved in self-reflective learning and independent learning, whilst academics within science and engineering fields tend to conceptualize creativity as visible in the processes of producing something, showing multi-perspectives, and reaching for original, entirely new ideas. These authors, however, also explain that there remains significant ambiguity, particularly in terms of how creativity is understood by actors in different disciplinary contexts, calling for further research to be conducted in this area [20]. This sentiment is echoed by Jackson and Shaw [8], who agree that "to extend our understanding of creativity in higher education we have to elaborate the meanings of creativity and the way it is operationalized in each disciplinary field" (p. 89).

Scholars have recognized that perceptions of creativity as expressed by others, through either quantitative or qualitative research methods, remain difficult to interpret. Quantitative measures, particularly Likert-type responses, common in creativity research, are known to be insufficient in circumstances where interpretation is known to vary amongst participants $[22,23]$. However, when considering the perceptions of different groups, even qualitative methods are not immune from such validity issues. As Edwards et al. [24] put it, when describing the interpretation of creativity from different disciplinary groups, " ... the issue of meanings emerges once more. Did academics in mathematics departments 'mean' quite the same thing as those in arts departments when speaking about 'creativity' and 'the new', for example?" (p. 71).

The most influential theoretical model that is used to account for differences, including differences in interpretations, remains Csikszentmihalyi's systems model [11]. The systems model of creativity proposes that creativity is a "process that can be observed only at the intersection where individuals, domains, and fields interact" (p. 314), offering recognition to elements overlooked by purely psychological approaches to creativity, which tend to focus on the individual. With this model, the 'domain' refers to the discipline's "existing objects, rules, representations, or notations" (p. 315). Csikszentmihalyi explains that creativity 
occurs when a relatively permanent change is made to the domain by an 'individual'. Not all changes are accepted, however, and thus, the 'field' refers to the actors or groups who act as gatekeepers to determine which changes are sustained over time (p. 315). Though the systems model of creativity represented a considerable development in creativity theory in that it acknowledged factors beyond the individual mind, the domain and the field elements of the system remain undertheorized, and their connection to the individual thus remains fragile. Glăveanu [25], for instance, explains that "we are missing ... a theory that relates ... individual-level outcomes to the social and cultural contexts that help them come into being (p. 335)".

It is within this context that we undertake the current qualitative study. To make sense of the data, we draw on sociological theory, here, Legitimation Code Theory (LCT), to conceptualize the nature of creativity as viewed through different disciplinary perspectives. That is, we use LCT to provide a way to characterize knowledge, or Csikszentmihalyi's 'domain'. In this research, the domains of interest include the academic disciplines of physics, history, and poetry. In this research, we consider the academic fields of physics, history, and poetry because they represent the considerable variation in knowledge and inquiry practices identified in scientific and social sciences fields [26]. Such a comparative approach has proven useful in studies of literacy and sociology, where studying an object in relation to others provides insight beyond study of the one object in isolation, e.g., [21,27]. In studying creativity through the lens of these three disciplines, we also hope to understand the nature of creativity within and across disciplines in a more detailed way.

\section{Theoretical Framework}

In characterizing knowledge and inquiry practices, we begin with the Bernsteinian delineation of everyday knowledge and academic knowledge and the further classification of the latter as consisting of "horizontal" and "hierarchical" knowledge structures [28]. Bernstein's horizontal knowledge structures represent domains where knowledge consists of a "series of specialized languages, each with its own specialized modes of interrogation and specialized criteria for the construction and circulation of texts" (p. 162). Horizontal knowledge structures develop through the addition of new set of languages because "the set of languages which constitute any one horizontal knowledge structure are not translatable, since they make different and often opposing assumptions" (p. 163). Horizontal knowledge structures are common in the humanities and social sciences, for example, English literature, philosophy, and sociology, where different, often contradictory "perspectives" on a subject can co-exist. Hierarchical knowledge structures are "explicit, coherent, systematically principled" (p. 161), where knowledge develops through integration "at lower levels" and "across an expanding range of apparently different phenomena" (p. 162). Such hierarchical structures can be found in disciplines such as biology or physics, where "uniformities" are integrated and subsumed into more "general" frameworks, such as theories and laws.

Within the creativity literature, the nature of the discipline (or 'domain') has been discussed to some degree as a factor that plays a role in giving creativity its distinctive character, in a way consistent with Bernstein's classifications [29,30]. For instance, Li [30] describes domains with horizontality as able to "allow novelty to occur in all dimensions, resulting in divergent developments of the domain ...", whilst domains with verticality "possess certain stable elements that are existentially fundamental to the domain, thus permitting alteration only around certain dimensions" (p. 107). Keinänen et al. [29] draw on Li's conceptualization within their concepts of "axis" and "focus". Axis reflects the degree of constraint (vertical for a higher degree of constraint and horizontal for fewer constraints). Focus refers to the degree of discreteness (modular versus broad tasks). The example given by these authors is of different forms of dancing: ballet exhibits a vertical axis and modular focus due to its adherence to specific positions and movements and prescribed choreographed pieces and where dancers develop expertise in a single form of movement. In contrast, modern dance is horizontal in its orientation and with a broad focus because the ethic of modern dance is to challenge tradition. Modern dancers are more 
likely to exhibit expertise in a wider range of movements compared to traditional ballet dancers. Of course, there are subdomains of ballet and modern dance that challenge these characterizations, just as there are different subdomains of law, physics, and business that vary, in some cases, quite substantially. Thus, although these descriptions, including the Bernsteinian description, are consistent with each other and the illustrations provided, they do not offer a way to systematically analyse practices.

We thus draw on Legitimation Code Theory (LCT), a conceptual framework that builds on Bernstein's knowledge structures, in order to take a more analytical and systematic approach to the empirical data. LCT operationalizes different types of knowledge through a construct known as Specialization, which is founded on the premise that "practices are about or oriented towards something and by someone" [31] (p. 12). Specialization thus conceptualizes the relationships between practices and their object (known as epistemic relations) and practices and their subject (known as social relations). For example, physics is a "hierarchical" discipline known to be represented by stronger epistemic relations and weaker social relations: "possession of specialized knowledge, principles, or procedures concerning specific objects of study is emphasized as the basis of achievement, and the attributes of actors downplayed" [31] (p. 12). As a contrastive example, weaker epistemic relations and stronger social relations characterise more "horizontal" disciplines where "specialized knowledge and objects are downplayed, and the attributes of actors are emphasized as measures of achievement, whether viewed as born (e.g., 'natural talent'), cultivated (e.g., 'taste'), or social (e.g., 'feminist standpoint theory')" [31] (p. 12). The key to the operationalization of Specialization is that social relations and epistemic relations can vary in degree along a continuum, giving us an analytical tool known as the specialization plane and the associated four specialization codes that constitute the quadrants in Figure 1 [31].

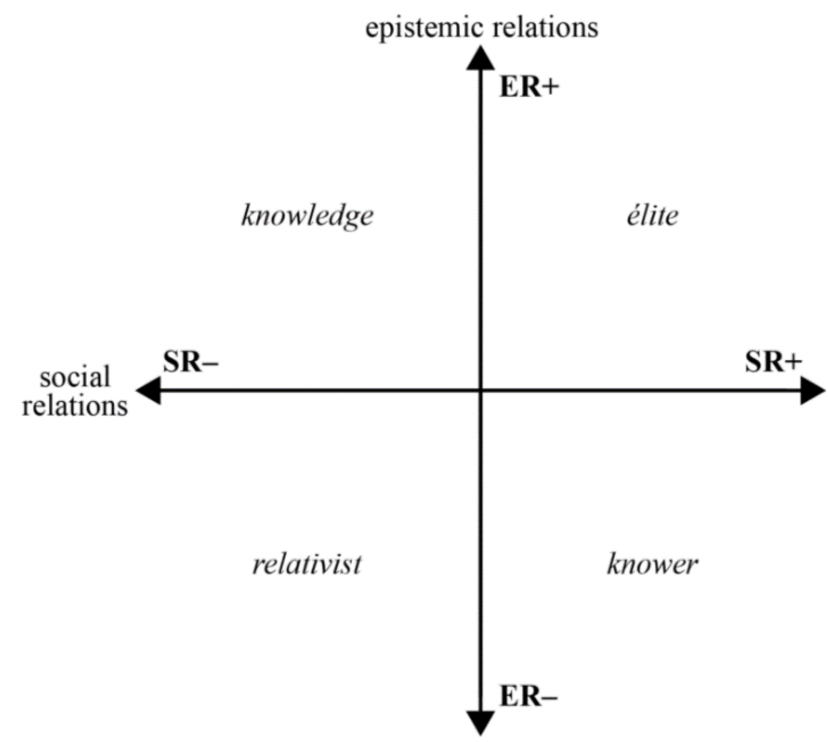

Figure 1. The specialization plane. Reprinted with permission from Ref. [31] (p. 30). Copyright 2014 Routledge. Knowledge codes emphasize what you know, knower codes emphasize who you are, élite codes emphasize both specialized knowledge and the right kind of knower, and relativist codes are "anything goes" (www.legitimationcodetheory.com (accessed on 20 January 2022)).

\section{Materials and Methods}

\subsection{Recruitment}

Data for this research included 10 semi-structured interviews with experts who were also university teachers in Australia in their respective fields: three each from physics and poetry and four from history. The interviews were 45-60 min in duration. The participants were recruited via purposive sampling through personal contacts, direct contact due to public eminence, or through recommendation. Participants ultimately 
recruited had significant and recognised expertise in the relevant discipline, for example, being a professor of physics or a published poet. The use of purposive sampling allowed the team to gather relevant information-rich cases that would illuminate the research area [32]. To achieve adequate representation, engage more diverse views, and to minimize selection bias, participants were asked to consider whether other experts in their field would hold the same views as themselves. This resulted in the targeting of two additional participants. The first was a physicist in the applied field (engineering), suggested by one of the physics experts who happened to be an astronomer (considered a more "fundamental" science). The second was an historian who, in contrast to the other three historians, was known to be (a) more conservative and (b) focused on ancient history rather than on modern. As an example of sample selection within physics, the physics participants were recruited through: (P1) contact with head of teaching and learning of the school of physics who provided recommendation of P1, amongst others; (P2) direct contact of current practicing physicist who conducts significant outreach and has published popular physics books; and (P3) direct contact based on disciplinary expertise and university specialism (university was a leader in this field of applied physics), based on recommendations from P1 and P2 who were from the same field (Astronomy).

\subsection{Data Sources}

Interviews were conducted using a semi-structured interview protocol designed for the study and focused on the distinctiveness of each discipline and how creativity is understood and is manifest in it. The interview protocol was designed to capture the experts' perceptions of the nature of their discipline and the understandings of creativity within it and included indicative interview questions, such as "What does it mean to be creative in poetry/physics/history?", "How is this different to other disciplines?", and "What is distinctive about your discipline?". The interview recordings were transcribed verbatim with all participants recorded under pseudonyms and entered into NVivo for analysis.

\subsection{Analysis}

The interview data were coded thematically and inductively by the research team, focusing on how creativity was perceived by expert practitioners in their discipline. We follow Jahnke et al.'s [22] approach, which involved eschewing the imposition of an external definition of creativity to instead focus on the "inside view" or "how university teachers grasp, explain, and describe creativity" (p. 89). The analytical process involved considerable negotiation, and we endeavour here to make this process as transparent as possible [33]. This process of inductive coding resulted in the identification of a large number of emergent codes by the two coders (authors 1 and 2) on a sample of four interview transcripts. During this stage, consistency of the code assignment was checked, both internally and with reference to the extant literature, and a number of codes were merged and labels adjusted to better reflect their focus. Through these discussions, relationships between the codes emerged as thematic clusters and were grouped subsequently under the following seven themes: Making Connections, Constraint, Composing Narratives, Expressing Self, Imagining, Playing with Language, and Problem Solving. The researchers (Authors 1, 2, 3, and 4) then used these codes to independently code a single interview transcript before coming together to discuss and refine the coding decisions again. Two of the researchers (A1 and A2) tested reliability of coding in three transcripts within NVivo. Cohen's kappa was calculated within NVivo, giving equal weighting to all nodes/sources and returned a value of 0.82 , which represents "very good" agreement-the highest category. The Cohen's kappa further served to highlight any inconsistencies in the assignments to each code, which, following discussion, enabled the focus and boundaries of each code to be refined. This was a significant step in improving the precision of the coding framework before the final stage of checks. 
Finally, coding was also checked by the remainder of the research team through two main channels: open coding with the existing code book and code checking of individual codes. Only minor changes were made at this stage. The final seven themes, their elaboration, and example excerpts are provided in Table 1.

Table 1. Codes representing identified themes and their descriptions.

\begin{tabular}{|c|c|}
\hline $\begin{array}{l}\text { Theme/Code } \\
\text { Code Description }\end{array}$ & Representative Excerpt \\
\hline $\begin{array}{l}\text { Making Connections } \\
\text { Creativity as making new connections between ideas, } \\
\text { constructs, or fields. }\end{array}$ & $\begin{array}{l}\text { "Yes, it's just trying to find those really unusual things that you } \\
\text { don't expect and looking at your sources and trying to think } \\
\text { about them in a way to be like, 'Well, where did this come from? } \\
\text { Is it all on the paper here or is there ... ?" (History) }\end{array}$ \\
\hline $\begin{array}{c}\text { Constraint } \\
\text { Working within constraints/boundaries; } \\
\text { Creativity as being constrained or as ultimate freedom }\end{array}$ & $\begin{array}{l}\text { "I think our creativity ... I think of it as like a really structured } \\
\text { creativity." (Physics-constraint) } \\
\text { "There's no rules for writing poetry in the way that it has to look } \\
\text { for structure or form. It doesn't have to rhyme." And the other } \\
\text { rules would be, "Today, I self-express, and whatever that } \\
\text { sounds or looks like is great." (Poetry-freedom) }\end{array}$ \\
\hline $\begin{array}{l}\text { Imagining } \\
\text { Creativity as viewing things in different ways or from a } \\
\text { different perspective outside of known possibilities }\end{array}$ & $\begin{array}{l}\text { "If they personally have some experience and connection with it } \\
\text { in their family or themselves or so on, they might be able to } \\
\text { bring a different imagining from somebody who doesn't have } \\
\text { that kind of relationship to it." (History) } \\
\text { "We're a lot like literary writers although we aspire to write as } \\
\text { closely to the past as we can, but it's always a process of } \\
\text { imagining because we can't actually go to the past; we can't put } \\
\text { everything into our histories." (History) }\end{array}$ \\
\hline
\end{tabular}

\section{Composing Narratives}

Creativity as storytelling to communicate meaning so as to engage an audience.
"So, part of the creativity in history is, well, okay, so you've got the history but it's how you present it and how you present it in a way that impacts people and can affect social change or whatever." (History)

"To be creative in poetry means to self-express. Yeah, just to self-express, and in multiple forms." (Poetry)

Creativity as expressing identity and being self-reflective.

\section{Playing with language}

Creativity as experimenting with language.

\section{Problem solving}

Creativity as exploring to make sense of problems and find solutions
"I mean, you're not making sense of it; in some ways, you're taking it apart and reconstructing it or making new meaning for things, and that in itself I think is quite challenging and also very exciting and inspiring a sort of process." (Poetry)

"Creativity finding better and more efficient solutions." (Physics)

\section{Results}

Seven thematic codes resulted, which reflect participants' perceptions of the nature of creativity in physics, history, and poetry (Table 1). It is important to note that each of the themes was not present in all discipline groupings. Figure 2 shows the number of coding references for each theme across the three discipline areas.

The themes of Making Connections, Constraint, and Imagining exhibited a strong presence within the three discipline groups of participants, whilst Composing Narratives was mainly exclusive to history, Expressing Self and Playing with Language were exclusive to poetry, and Problem Solving was mainly confined to physics, with only one reference in both poetry and history. 


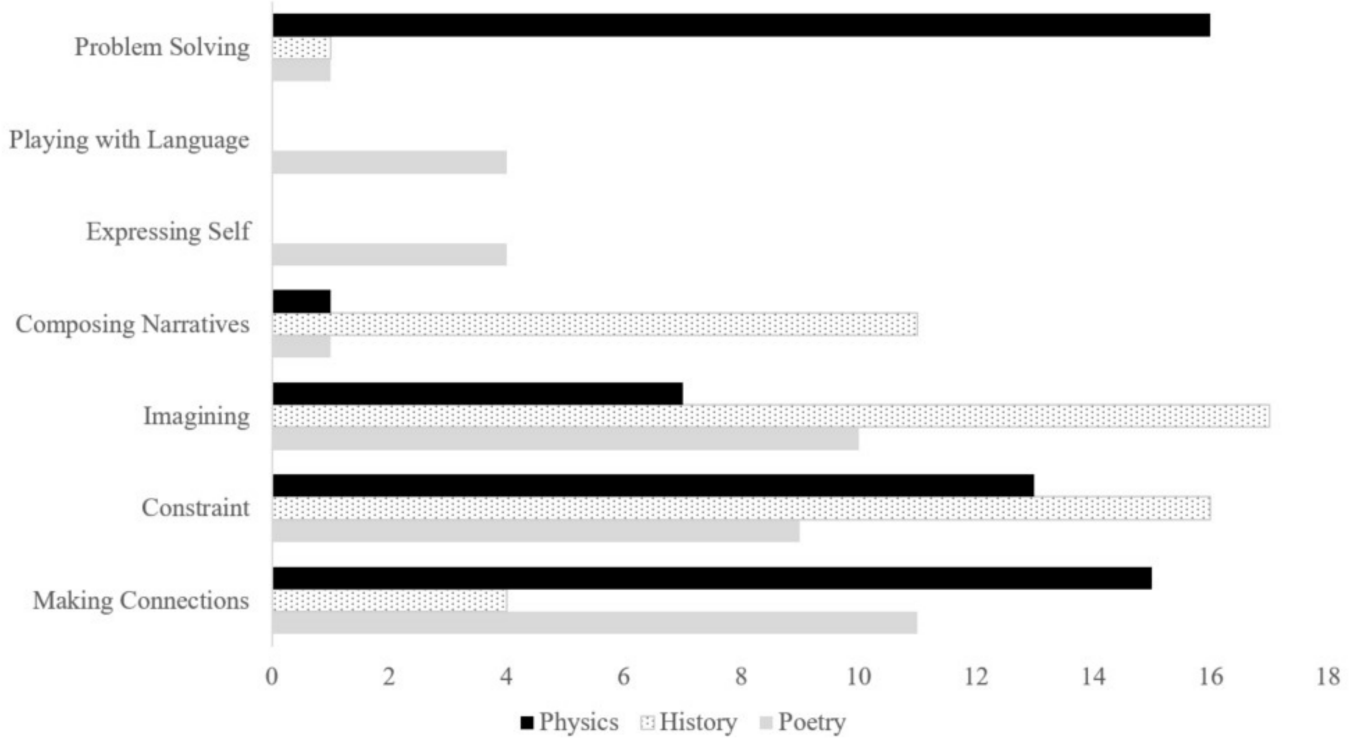

Figure 2. The distribution of themes in each discipline area. The $x$-axis represents number of coding references.

\subsection{Making Connections}

Making Connections was a theme where creativity was described as making new connections between ideas, constructs, or fields. What was key to this theme was the novelty of the connections made, with links made being unexpected or surprising and involving discrete and likely disparate entities. Across the three disciplines however, although the concept of Making Connections was common, the practices involved differed. For example, in history, participants discussed the creativity in making "lateral connections", making reference to the archives specifically. In physics, the connections were being made between existing knowledge or observations and "the latest theoretical thinking" or "pieces from here and pieces from ... different subjects". Interestingly, one of the physics experts and another history expert framed this as a series of questions, exemplifying how the differences in the substance of "creative connections" might manifest in the creative process:

"What's the latest theoretical thinking? Why doesn't this theoretical thinking match those observations? What if we do this, do that? ... This doesn't look right. How would I fix that?" (Physics)

"Well, where did this come from? Is it all on the paper here or is there ... ? You know, sometimes it's just looking close and being like, 'Hang on a minute. That date doesn't accord to what I expected.'" (History)

In poetry, the connections made were discussed in fairly distinct ways by each of the three participants. One poet with a strong linguistics background made explicit connections between language and meaning: "All those strata ... co-exist; the sounds that are alike and the meanings that are alike and the words that are alike and the grammatical structures that are alike-they're all co-existing". Poetry in this participant's account involved a moment of creative inspiration, where the graphological, phonological, and semantic experience of language coalesce simultaneously in multiple ways. Another poet, however, emphasized instead how creativity in poetry fostered connections between experiences and people:

"You're capturing the experiences of a person or the beliefs or perceptions of a person and interacting with those in some way, whether they're, you know, on the stage for theatre or in a collection of poems." (Poetry)

\subsection{Constraint}

The theme of Constraint represents a scale that is bookended by complete freedom and strong boundaries. Where this theme is identified in participants' responses, it represents perspectives of creativity that sit somewhere on this scale. On the one hand, creativity 
was conceptualized as being spontaneous, unbounded, or not limited by conventions or rules. On the other, it was also perceived as only evident in relation to existing structures, knowledge, and norms and only made possible because of them. Of the 38 total references coded to Constraint (see Figure 2), 35 referred to some element of constraint, whilst only 3 referred to ultimate freedom. All three of the freedom references originated in the one poetry interview, where the participant described poetry as "the freest way to engage in creative self-expression" through "freeform rather than through something really rigid like prose" because "there's no rules for writing poetry in the way that it has to look for structure or form. It doesn't have to rhyme ... whatever (self-expression) sounds or looks like is great". The importance of openness and possibility as central to creativity are pervasive ideas in the poetry interviews, with poetry as a form offering expressive possibilities: "I think poetry and its intensification is this alertness to the possibilities of every stratum". Alongside the descriptions of potential freedom, two of the poets discuss creativity in poetry as adhering to some degree of constraint: it was reducing ideas to "pure meaning, through words", which, in fact, was more difficult than in prose, where "you've got the capacity to expand and expand". Rather, in poetry, the constraint is doing it in a concentrated way: "you've probably got about eight lines".

In history, Constraint was mentioned with respect to being accountable to empirical verification. Views ranged from being constrained by the actual firsthand evidence to being constrained by accountability.

In physics, there was a strong view that "nature is the arbiter," and that you "still have to agree with the data". In a sense, this is similar to the discussion about empirical evidence in history although there was a key difference. In physics, to be creative, participants indicated that individuals are not only constrained by the data but also by all the theories and models that were generated from them: "you need to know that [why other theories have fallen by the wayside] ... as part of that input into your creative process ... It's constrained thinking". The notion of Constraint and the strong link between creativity and constraint is highlighted in the quotation below:

"So, it's a really structured, constrained creativity, and I think that's why it's hidden sometimes ... some people can't see that from the outside, but actually, it's a kind of creativity that then it's quite hard to find because you have to absorb everything that's already known and then try and figure out new things in that context." (Physics)

\subsection{Imagining}

Represented within this theme is an understanding of creativity as involving a moment of imagination, speculation, or hypothesizing. It encompasses "thinking outside of the box" or envisioning possibilities that may be unusual or unexpected and at times involving the adoption of alternate viewpoints. Often, participants will characterize creativity as necessitating "seeing things from a different perspective" or will discuss taking a "new" approach.

An ability to speculate or imagine is described as being central to history due to the incomplete nature of historical data: "the problem, the further back you go is, you get fragments; fragment here, fragment there. And then, you get whole periods of time that are badly covered, so it's very difficult. And in a sense, that's where creativity comes in". This form of thinking is described as having the potential to be a transgressive act, as the individual may need to challenge orthodoxy, confront previously held conceptions, or challenge the interpretation of others. To arrive at a new interpretation of history, the individual has to imagine an alternative to established narratives or histories. Unlike Constructing Connections, the key to this theme is a moment of speculation where the individual imagines data that are inaccessible, unknown, or silenced. It is not so much a matter of connecting potentially disparate sources but rather thinking of what evidence might as yet be undiscovered or whose voices might be missing from historical accounts: "So, I'd say, looking at ... and saying, 'where are the gaps in these stories? Whose voices are we not hearing? What stories are not being told?"' Similarly, in physics, this process 
of seeing differently might mean using established disciplinary thinking or processes in different or unexpected ways:

"The ability to look at something and think about it and for it to click in a way that it's never clicked with anybody else ... the best things is when you see it, you say, 'Why didn't I think of that' and you ... just sort of go, 'That's now so obvious. Why didn't we think of that earlier?' kind of thing." (Physics)

There is perceptible tension within this theme, as the individual needs to negotiate the boundaries of their speculations. The respondents noted that not all creative interpretations were acceptable to the field, as they had to satisfy disciplinary demands of credibility, as encapsulated in the extract below:

"And so, you know, it is a creative, imaginative, speculative, responsible process, and the only way that we know of how to give that credibility, or warrantability is a better word, is that it's a collective process; we have to put our ideas in a public forum where you have to have our colleagues and the public comment on them ... If you just imagine your history without putting it out for collective discussion, it's not a history." (History)

This theme manifests differently in poetry, where the individual is encouraged to embrace another's perspective to imagine the way that the other might use language or make meanings as they write. This can involve seeing as another might, rather than seeing "differently," with the poet adopting multiple and alternative perspectives on the world to be able to look with "new eyes." In poetry, this process of seeing from another perspective is more somatic and enables the poet to conceive of other ways of making meaning poetically: "if you can start thinking about different ways of constructing them [words] and putting them in particular forms and so on-different languages and cultures have different ways of locating those words and sentences. So, you know, let's look at how we might locate the world differently in those words and sentences and structures."

The themes that will be discussed next were not commonly expressed across the dataset, tending to emerge within distinct disciplinary contexts.

\subsection{Composing Narratives}

Composing Narratives emerged as a distinct theme in interviews with the history experts. Mentioned by all four participants, this theme was identified as a key creative endeavour in the discipline; typical of their comments is this one: "For me, the creativity is the writing aspect of how to bring the past to life and to write in a compelling sort of way". In retelling historical content, the participants describe a conscious attention to the delivery of historical content. Creativity is described as central to communicating history in a novelistic manner in order to capture the reader's attention. For some respondents, the re-telling of history also involved presenting the content persuasively to effect real-world change: "So, part of the creativity in history is, well, okay, so you've got the history, but it's how you present it and how you present it in a way that impacts people and can affect social change". Producing a narrative appears to provide a creative impetus for the discipline, with the writing process involving the careful selection of information to be included-“You have to decide what you're going to leave out and what you're going to put in,"- as well as focusing on the lyricism of the account: "Good history will sing to you". An appreciation of "creative" writing in terms of the aesthetics of the form emerges from the interviews: "I think if you read good history, it is, at its core, creative because a good history will sing to you; it is beautifully written; it's telling a narrative that you want to know what happens next. That in itself, to me, is a creative endeavour".

\subsection{Expressing Self}

Personal expression was captured as a minor theme isolated to one poetry participant's responses. From their perspective, creativity is an opportunity to share aspects of oneself: "to be creative in poetry means to self-express. Yeah, just to self-express, and in multiple forms". Pervasive in this description is the absence of boundaries, with individuals able to express themselves in whichever forms they chose: "it's really special, and I guess 
poetry over other forms specifically because it feels like the freest way to engage in creative self-expression". Creativity is also described as a process of discovery, finding different dimensions to personal experiences as you use your writing to make connections to others:

"So, poetry has been self-expression, it's been mostly almost like a diarised version of events in my life, or self-exploration around different understandings of things, in experiences of people, places, and records of those things and an attempt to bring connection to other people into that experience and to find some kind of unity across those experiences." (Poetry)

\subsection{Playing with Language}

Emerging from all of the poetry interviews was an account of creativity as "experimental play with words". Creativity is described as an active process, exploring how language can be reshaped, restructured, and reformed. This involves experimenting with sound, meaning, and visual appearance of language without an explicit end in sight. Instead, creativity is about discovering and making something new as captured in the following example:

"I think with any kind of creative writing, particularly poetry, you really are much more open to experimentation and play, and I think that that's a very important way of seeing the world differently. I mean, you're not making sense of it; in some ways, you're taking it apart and reconstructing it or making new meaning for things, and that in itself I think is quite challenging and also very exciting and inspiring a sort of process." (Poetry)

\subsection{Problem Solving}

Finding solutions to complex and often open-ended questions emerged as an aspect of creativity across the interviews. However, it was only in physics that problem solving appeared as a major theme with all three participants identifying it as a key aspect of creativity in the discipline. Significantly, these "problems" were often weakly defined or open-ended, without a clear or readily accessible solution: "Real creativity comes when there isn't an answer". As a result, many of the tasks set for tertiary students were not considered to be creative as solutions were already known. In physics, Problem Solving is described as involving a series of processes, moving from considering problems anew to identifying appropriate methodologies, to then testing and retesting possible solutions, and eventually arriving at an appropriate solution. The physicists describe creativity as tending to emerge when individuals use new or untried methodologies to access solutions; for example, "She did something that a whole team of about 1000 people in total had never done". Solutions valued as "creative" by the participants were described as being "new" or "innovative" or as offering greater efficiency or utility: "Creativity [is] finding better and more efficient solutions" as is demonstrated in the following excerpt: "Creativity is to develop something new, innovative, or make a discovery, you know, that really make a discovery, and it's something that typically, it's recognized to be useful, or we bring it to something, you know, to an end-point".

Although infrequently mentioned in poetry, one of the poet respondents offered a similar understanding of creativity as problem solving, pointing to creativity in poetry as finding solution for social problems: "For me, poetry enables us to conserve language and landscape through poetry in [Project name redacted], and so therefore, poetry is creative in the way that it comes up first with solutions".

\subsection{LCT (Specialisation)}

The dimension of Specialization from LCT was employed to suggest that interpretations of creativity in the respective academic disciplines differ along the two axes reflecting strengths of epistemic and social relations. That is, across the various themes, degrees of epistemic relations and social relations varied, ranging from weaker to stronger, and represented different positions on the Cartesian plane as well as different codes (Figure 1). A knowledge code assignment, which is characterized by stronger epistemic relations (ER+) 
and weaker social relations $(\mathrm{SR}-$ ), reflects coding references that emphasize the importance of empirical knowledge, such as in physics, where creative acts must agree with the data. A knower code, which is characterized by weaker epistemic relations (ER-) and stronger social relations $(\mathrm{SR}+)$ and, reflects coding references that emphasize the importance of the "knower," such as with history, when it is said that certain perspectives (e.g., Indigenous, female) are valued as part of the creative process.

A selection of assignments that are based on coding references across the themes and for the different disciplinary groups of participants is presented in Figure 3. Making Connections in physics can be described as a knowledge code $(\mathrm{ER}+, \mathrm{SR}-)$ since it relates to connections of knowledge, observations, and theories that can be understood and recognized as novel by those in the field and where "who you are" is not considered to be as important (Figure 3). In history, Making Connections similarly exemplified a knowledge code, with stronger epistemic relations associated with connections needing to align with records, material remains, or sources. However, participants explained that there was always some element of interpretation in Making Connections, thus its placement at a position of weaker epistemic relations and stronger social relations compared to physics. Creativity in history was also characterized as a knower code. In Imagining, for example, creativity in history is described as engaging perspective of voices that have been silenced or absent from the earlier historical accounts, such as Indigenous, immigrant, or feminist voices. This highlights the value placed on the who rather than the what. In poetry, however, different individual participants exemplify different specialization codes across as well as within the themes. For instance, within the Making Connections theme in one interview, epistemic relations were stronger (focusing on the use of language and form to make novel connections), reflecting a knowledge code, whereas a separate interview reflected a knower code within this same theme, as the participant described using poetry to identify and connect with the local community. Finally, within Self-Expression, a strong theme only present in one participants' interview, we observe a relativist code in LCT (Figure 3), as the participant describes a space where "anything goes" (in terms of constructing poetry).

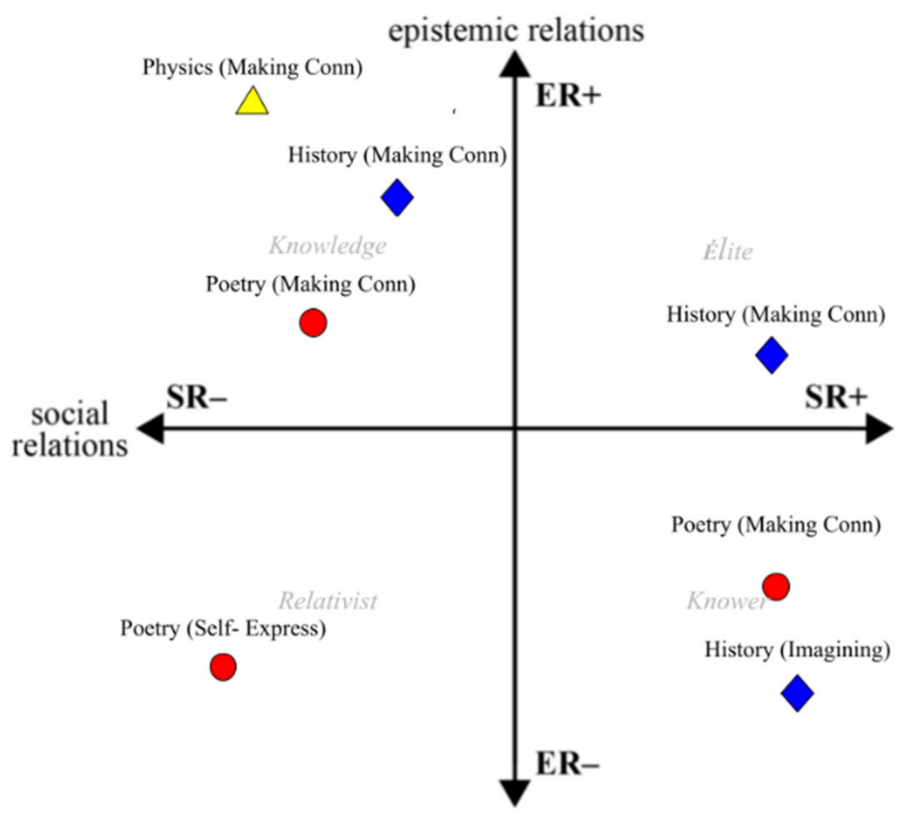

Figure 3. Specialization codes for themes and discipline areas on the specialization plane.

\section{Discussion}

In conducting this research, we sought to provide a conceptualization of creativity drawing on perceptions of creativity from participants of three academic disciplines. Uniting the experts' accounts of creativity was the assertion that theirs was a creative discipline 
and that creativity was recognized as inherent to their disciplinary practices. This supports the longstanding understanding that all disciplines exhibit and are driven by creative acts [34,35]. Again, consistent with the extant literature, emerging themes included imagining solutions to problems and composing narratives [8], seeing the world from new perspectives [8], and making new or lateral connections [9].

We draw on Specialization from Legitimation Code Theory to make sense of these descriptions. Specialization conceptualizes creativity in the different disciplines as exhibiting different relative values of epistemic relations ("what you know") and social relations ("who you are"). Specialization is the most elaborated and enacted dimension in LCT, which itself is an emerging framework in education [31]. In coding the perspectives of participants in relation to creativity, we present two main findings: first, that the nature of creativity is notably distinct in terms of the specialization codes observed. Discussions of creativity in physics show that the concept is understood to be relatively consistent and stable-a knowledge code. Creative acts occur, for instance, when connections are made between empirical measurements and existing or developing models and theories. Discussions of creativity were similar in nature for all three participants. In contrast, different aspects of creativity were discussed amongst both history and poetry experts as knowledge, knower, élite, and relativist codes, thus having a more varied quality (Figure 3). For instance, historical creativity was discussed as representing a knowledge code, as connections were being made between different empirical sources. At the same time, creativity in history could also involve reconceptualising historical events through different lenses, such as feminist or Indigenous perspectives, constituting a knower code. Creativity was discussed most disparately amongst the poetry experts. A knowledge code perspective describes creativity as occurring when connections are made between the different strata (levels) of language, whilst creativity was also described as a knower code in that it was used as a way to make connections to community. In one interview, creativity in poetry was also described as a relativist code: "anything goes" (as long as it is a form of self-expression).

Differences in how creativity is perceived in each field and the consensus regarding those perceptions strongly implies that although the same language could be used to describe different facets of creativity, what they represent is substantially different, as they refract differently through distinct disciplinary architectures. Theoretically, we can thus describe practices as either having more transient/fluid architectures (poetry), with notions of creativity shifting between various specialization codes, or showing more consistency (physics) and reflecting notions of creativity that are more universally understood. It is understood that fields and social structures play a role in understanding creativity $[13,26]$ and also that disciplinary differences influence the nature of creativity in these disciplines $[29,30]$, but theorization of disciplinary knowledge does not constitute a large part of creativity research.

Ultimately, this work aims to bring clarity to the notion of creativity so that it might be more fruitfully discussed in higher education contexts. There has been considerable work focused on describing creativity, e.g., [19-21], but we know that these descriptions remain variously interpreted and differently emphasized, meaning it is difficult to conclude to what degree each is present or foregrounded in any specific context and why [10,22]. Further, researchers argue that theoretical descriptions remain difficult to utilize in practice [15-17], and perhaps accordingly, the considerable work in the field of creativity has so far failed to produce any meaningful change in teaching and learning [7]. The status quo in higher education is identified as a lack of expression of creative outcomes at the subject level [8] or an overly generic representation of creativity as a "soft skill" or graduate attribute that is rarely assured [6]. In order for creative outcomes to be effectively fostered, creative outcomes must be explicitly stated in curricula, assessed, and taught [6]. As a sociological framework, LCT's power is in revealing "what lies beneath." That acts of creativity need to be intelligible within the field of study (whether that be physics, history, or poetry) is important, as otherwise, creative contributions may not be recognized as such in the discipline (and vice-versa) [36]. Accordingly, and as universities become more centralized 
and interdisciplinary, consideration of the organizing principles of the disciplines is apt in order to understand creativity both within and across fields and, in particular, in order to express and foster creativity in teaching and learning.

\section{Limitations and Future Work}

In general, limitations that apply to other studies of this nature can also be applied here, particularly those regarding small sample sizes. The perspectives of 10 (or 3 ) participants cannot be assumed to be representative of higher education or their respective disciplines. Accordingly, caution needs to be exercised in generalizing from these responses; however, the data suggest distinctively different perspectives on creativity across the domains, as found in a range of other studies, e.g., $[8,20]$.

In terms of future work, LCT (Specialization) may prove fruitful in identifying inconsistencies or incongruences between generic goals, course or subject learning outcomes, teaching and learning activities, and assessments, as in [37], where the incongruence of another generic skill, academic readiness, was explored within a foundational science course at a South African university. Similarly, further analysis might explore specific tensions using the notion of "code clashes," e.g., [31,38]. A code clash describes a situation where the specialization codes of practices are not consistent with one another, leading to difficulties in achieving educational objectives. It is likely that code clashes might occur when actors within one discipline attempt to understand creativity in another or when programs observing and attempting to foster creativity are applied across different disciplinary contexts. More generally, a larger sample size and inclusion of empirical data from different contexts (domains/disciplines) is also needed in order for theoretical understanding to be more profitably utilized in practice, in particular, in educational institutions, where curricula and assessments, including those for creativity, are enacted.

Author Contributions: Conceptualization, H.G., A.T., E.M., P.J., P.G. and C.E.-G.; Data curation, H.G., A.T. and P.J.; Formal analysis, H.G. and A.T.; Funding acquisition, H.G. and P.J.; Investigation, H.G., E.M., P.J. and C.E.-G.; Methodology, H.G., E.M., P.J. and P.G.; Project administration, E.M. and P.J.; Software, H.G. and A.T.; Validation, E.M., P.J. and P.G.; Writing-original draft, H.G. and A.T.; Writing-review and editing, H.G., E.M., P.J., P.G. and C.E.-G. All authors have read and agreed to the published version of the manuscript.

Funding: This research received no external funding.

Institutional Review Board Statement: The study was conducted in accordance with the Declaration of Helsinki, and approved by the University of Wollongong Human Research Ethics Committee (\#2018/509).

Informed Consent Statement: Informed consent was obtained from all subjects involved in the study.

Data Availability Statement: Not applicable.

Conflicts of Interest: The authors declare no conflict of interest.

\section{References}

1. Vincent-Lancrin, S.; González-Sancho, C.; Bouckaert, M.; De Luca, F.; Fernández-Barrerra, M.; Jacotin, G.; Urgel, J.; Vidal, Q. Fostering Students' Creativity and Critical Thinking: What It Means in School; OECD Publishing: Paris, France, 2019.

2. Gonski, D.; Arcus, T.; Boston, K.; Gould, V.; Johnson, W.; O’Brien, L.; Perry, L.-A.; Roberts, M. Through Growth to Achievement: Report of the Review to Achieve Educational Excellence in Australian Schools. 2018. Available online: https://www.dese.gov.au/quality-schools-package/resources/through-growth-achievement-report-review-achieveeducational-excellence-australian-schools (accessed on 20 January 2022).

3. Australian Curriculum Assessment and Reporting Authority. Critical and Creative Thinking. 2015. Available online: https: //www.australiancurriculum.edu.au/f-10-curriculum/general-capabilities/critical-and-creative-thinking/ (accessed on 20 January 2022).

4. OECD. Framework for the Assessment of Creative Thinking in PISA 2021 (Third Draft). 2019. Available online: https://www. oecd.org/pisa/publications/PISA-2021-creative-thinking-framework.pdf (accessed on 20 January 2022). 
5. Hager, P.; Holland, S.; Beckett, D. Enhancing the Learning and Employability of Graduates: The Role of Generic Skills; Business/Higher Education Round Table: Melbourne, Australia, 2002; p. 6.

6. Oliver, B.; Jorre de St Jorre, T. Graduate attributes for 2020 and beyond: Recommendations for Australian higher education providers. High. Educ. Res. Dev. 2018, 37, 821-836. [CrossRef]

7. Sternberg, R.J. Teaching for creativity: The sounds of silence. Psychol. Aesthet. Creat. Arts 2015, 9, 115-117. [CrossRef]

8. Jackson, N.; Shaw, M. Developing subject perspectives on creativity in higher education. In Developing Creativity in Higher Education; Jackson, N., Shaw, M., Oliver, M., Wisdom, J., Eds.; Routledge: Abingdon, UK, 2006; pp. 109-128.

9. Marquis, E.; Radan, K.; Liu, A. A present absence: Undergraduate course outlines and the development of student creativity across disciplines. Teach. High. Educ. 2017, 22, 222-238. [CrossRef]

10. Runco, M.A.; Jaeger, G.J. The standard definition of creativity. Creat. Res. J. 2012, 24, 92-96. [CrossRef]

11. Csikszentmihalyi, M. Implications of a systems perspective for the study of creativity. In Handbook of Creativity; Sternberg, R.J., Ed.; Cambridge University Press: Cambridge, UK, 1999; pp. 313-328.

12. Beghetto, R.A.; Kaufman, J.C. Toward a broader conception of creativity: A case for "mini-c" creativity. Psychol. Aesthet. Creat Arts 2007, 1, 73. [CrossRef]

13. Rhodes, M. An analysis of creativity. Phi Delta Kappan 1961, 42, 305-310.

14. Said-Metwaly, S.; Van den Noortgate, W.; Kyndt, E. Approaches to measuring creativity: A systematic literature review. Creat. Theor.-Res.-Appl. 2017, 4, 238-275. [CrossRef]

15. Craft, A. The limits to creativity in education: Dilemmas for the educator. Br. J. Educ. Stud. 2003, 51, 113-127. [CrossRef]

16. Plucker, J.A.; Beghetto, R.A. Why Creativity Is Domain General, Why It Looks Domain Specific, and Why the Distinction Does Not Matter. In Creativity: From Potential to Realization; Sternberg, R.J., Grigorenko, E.L., Singer, J.L., Eds.; American Psychological Association: Washington, DC, USA, 2004; p. 153.

17. Plucker, J.A.; Beghetto, R.A.; Dow, G.T. Why isn't creativity more important to educational psychologists? Potentials, pitfalls, and future directions in creativity research. Educ. Psychol. 2004, 39, 83-96. [CrossRef]

18. Bleakley, A. 'Your creativity or mine?': A typology of creativities in higher education and the value of a pluralistic approach Teach. High. Educ. 2004, 9, 463-475. [CrossRef]

19. Henriksen, D. The seven transdisciplinary habits of mind of creative teachers: An exploratory study of award winning teachers. Think. Ski. Creat. 2016, 22, 212-232. [CrossRef]

20. Jahnke, I.; Haertel, T.; Wildt, J. Teachers' conceptions of student creativity in higher education. Innov. Educ. Teach. Int. 2017, 54, 87-95. [CrossRef]

21. McLean, N.; Georgiou, H.; Matruglio, E.; Turney, A.; Gardiner, P.; Jones, P.; Edwards-Groves, C. Understanding creativity in primary English, science, and history. Aust. Educ. Res. 2021, 1-20. [CrossRef]

22. Katz-Buonincontro, J.; Perignat, E.; Hass, R.W. Conflicted epistemic beliefs about teaching for creativity. Think. Ski. Creat. 2020, 36, 100651. [CrossRef]

23. Plucker, J.A.; Makel, M.C. Assessment of creativity. In The Cambridge Handbook of Creativity; Sternberg, R.J., Ed.; Cambridge University Press: Cambridge, UK, 2010; pp. 48-73.

24. Edwards, M.; McGoldrick, C. Creativity and curricula in higher education: Academics' perspectives. In Developing Creativity in Higher Education; Jackson, N., Oliver, M., Shaw, M., Wisdom, J., Eds.; Routledge: London, UK, 2006; pp. 79-93.

25. Glăveanu, V.P. Rewriting the language of creativity: The Five A's framework. Rev. Gen. Psychol. 2013, 17, 69-81. [CrossRef]

26. MacDonald, S.P. Professional Academic Writing in the Humanities and Social Sciences, 2nd ed.; SIU Press: Carbondale, IL, USA, 2010.

27. Christie, F.; Maton, K. Disciplinarity: Functional Linguistic and Sociological Perspectives; Bloomsbury Publishing: London, UK, 2011.

28. Bernstein, B. Vertical and horizontal discourse: An essay. Br. J. Sociol. Educ. 1999, 20, 157-173. [CrossRef]

29. Keinänen, M.; Sheridan, K.; Gardner, H. Opening up creativity: The lenses of axis and focus. In Creativity and Reason in Cognitive Development; Kaufman, J.C., Bauer, J., Eds.; Cambridge University Press: Cambridge, UK, 2006; pp. 202-220.

30. Li, J. Creativity in horizontal and vertical domains. Creat. Res. J. 1997, 10, 107-132.

31. Maton, K. Knowledge and Knowers: Towards a Realist Sociology of Education; Routledge: London, UK, 2014.

32. Patton, M.Q. Qualitative Research E Evaluation Methods: Integrating Theory and Practice, 4th ed.; Sage Publications: London, UK, 2015.

33. Lincoln, Y.S.; Guba, E.G. Naturalistic Inquiry; Sage: Beverly Hills, CA, USA, 1985.

34. Gardiner, P. Playwriting pedagogy and the myth of intrinsic creativity. Res. Drama Educ. 2016, 21, 247-262. [CrossRef]

35. Sawyer, R.K. Explaining Creativity: The Science of Human Innovation; Oxford University Press: Oxford, UK, 2011.

36. Boden, M. Creativity and Knowledge. In Creativity in Education; Craft, A., Jeffrey, B., Liebling, M., Eds.; Bloomsbury Publishing: London, UK, 2001; pp. 95-102.

37. Ellery, K. Congruence in Knowledge and Knower Codes: The Challenge of Enabling Learner Autonomy in a Science Foundation Course. Reconfig. Found. Pedagog. Theor. Fram. 2019, 26, 213-239. [CrossRef]

38. Georgiou, H. Preservice teachers' views of the 'social embeddedness' tenet of the Nature of Science: A new method of analysis. $J$. Sci. Teach. Educ. 2022, in press. 